November 2000 - NREL/CP-520-28911

\title{
A Scanning Tunneling Microscopy Study of As/Ge(mnn) and P/Ge(mnn) Surfaces
}

\author{
W.E. McMahon and J.M. Olson
}

Presented at the $12^{\text {th }}$ American Conference on Crystal Growth and Epitaxy

August 14-18, 2000

Vail, Colorado

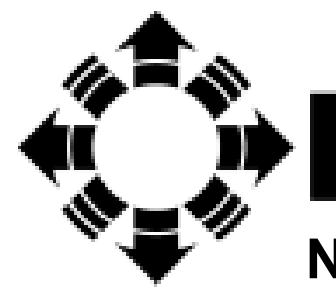

National Renewable Energy Laboratory

1617 Cole Boulevard

Golden, Colorado 80401-3393

NREL is a U.S. Department of Energy Laboratory

Operated by Midwest Research Institute $\bullet$ Battelle $\bullet$ Bechtel

Contract No. DE-AC36-99-G010337 


\section{NOTICE}

The submitted manuscript has been offered by an employee of the Midwest Research Institute (MRI), a contractor of the US Government under Contract No. DE-AC36-99G010337. Accordingly, the US Government and MRI retain a nonexclusive royalty-free license to publish or reproduce the published form of this contribution, or allow others to do so, for US Government purposes.

This report was prepared as an account of work sponsored by an agency of the United States government. Neither the United States government nor any agency thereof, nor any of their employees, makes any warranty, express or implied, or assumes any legal liability or responsibility for the accuracy, completeness, or usefulness of any information, apparatus, product, or process disclosed, or represents that its use would not infringe privately owned rights. Reference herein to any specific commercial product, process, or service by trade name, trademark, manufacturer, or otherwise does not necessarily constitute or imply its endorsement, recommendation, or favoring by the United States government or any agency thereof. The views and opinions of authors expressed herein do not necessarily state or reflect those of the United States government or any agency thereof.

Available electronically at http://www.doe.gov/bridge

Available for a processing fee to U.S. Department of Energy and its contractors, in paper, from:

U.S. Department of Energy

Office of Scientific and Technical Information

P.O. Box 62

Oak Ridge, TN 37831-0062

phone: 865.576 .8401

fax: 865.576.5728

email: reports@adonis.osti.gov

Available for sale to the public, in paper, from:

U.S. Department of Commerce

National Technical Information Service

5285 Port Royal Road

Springfield, VA 22161

phone: 800.553 .6847

fax: 703.605.6900

email: orders@ntis.fedworld.gov

online ordering: http://www.ntis.gov/ordering.htm

Printed on paper containing at least $50 \%$ wastepaper, including $20 \%$ postconsumer waste 


\title{
A Scanning Tunneling Microscopy Study of $\mathrm{As} / \mathrm{Ge}(\mathrm{mnn})$ and $\mathrm{P} / \mathrm{Ge}(\mathrm{mnn})$ Surfaces
}

\author{
W. E. McMahon* and J. M. Olson \\ *Corresponding Author: bmcmahon@nrel.gov \\ National Renewable Energy Laboratory \\ 1617 Cole Blvd., Golden, CO 80401 (USA)
}

\begin{abstract}
Ge(mnn) surfaces between (100) and (111) were annealed under either arsine or phosphine in a metal-organic chemical vapor deposition chamber, then imaged with a scanning tunneling microscope. In general, arsine-exposed $\mathrm{Ge}$ surfaces are facetted, while phosphine-exposed surfaces remain flat. For the arsine-exposed $\mathrm{Ge}$ surfaces, four stable facetting directions have been identified: (100), (11,3,3), (955), and (111).
\end{abstract}

PACS: 61.16.Ch, 68.35.Bs, 81.15.Gh

Keywords: STM, MOCVD, arsine, phosphine, germanium

\section{Introduction}

To better understand the nucleation of $\mathrm{GaAs}$ and $\mathrm{GaInP}_{2}$ on $\mathrm{Ge}$, we have performed a survey of Ge surfaces after exposure to either arsine $\left(\mathrm{AsH}_{3}\right)$ or phosphine $\left(\mathrm{PH}_{3}\right)$ in a metal-organic chemical vapor deposition (MOCVD) chamber. Vicinal surfaces with miscut angles between (100) and (111) were studied.

Our results for $\mathrm{AsH}_{3}$ exposure are quite different than for $\mathrm{PH}_{3}$ exposure. Most significantly, we find that $\mathrm{AsH}_{3}$ etches $\mathrm{Ge}$, whereas $\mathrm{PH}_{3}$ does not [1]. In addition, $\mathrm{AsH}_{3}-$ exposed $\mathrm{Ge}$ surfaces tend to facet. $\mathrm{PH}_{3}$-exposed surfaces remain flat, independent of the miscut angle.

The facetting of As/Ge surfaces has proven to be quite interesting, and will be the focus of most of this paper. For miscut orientations near (100) and (111), we find (100) and (111) terraces [1,2], in complete agreement with previously published results [3-8]. Prior to this study, little was known about the higher-angle miscuts, however. For this reason, models for nucleation on high-angle vicinal As/Ge surfaces are based on bulklike low-index surfaces such as (211).

In sharp contrast, our results show that low-index As/Ge surfaces such as (211), (311), (411), and (511) are neither bulk-like, nor are they stable under $\mathrm{AsH}_{3}$ exposure. Instead, we find that the stable As/Ge surfaces are (100), (11,3,3), (955), and (111). Furthermore, the $(11,3,3)$ and $(955) \mathrm{As} / \mathrm{Ge}$ surfaces are heavily reconstructed.

\section{Experimental Details}

All surfaces were prepared in an MOCVD chamber under 50-70 torr of $\mathrm{H}_{2}$ carrier gas flowing at 6-8 $\mathrm{L} / \mathrm{min}$. The group $\mathrm{V}$ source was either arsine $\left(\mathrm{AsH}_{3}\right)$, phosphine $\left(\mathrm{PH}_{3}\right)$, or background $\mathrm{As}_{4}$.

After preparation in the MOCVD chamber, samples were quenched to room temperature and transferred under vacuum to an ultra-high vacuum (UHV) chamber for study with low-energy electron diffraction (LEED), Auger electron spectroscopy (AES), 
and scanning tunneling microscopy (STM). All surfaces were studied as-quenched, with no additional surface preparation after leaving the MOCVD chamber.

\section{Definitions}

In this paper, the index (mnn) is limited to planes of the [01ㅣ zone with $\mathrm{m}>\mathrm{n}$. As shown in Figure 1, this spans a range of miscut orientations from (100) to (111).

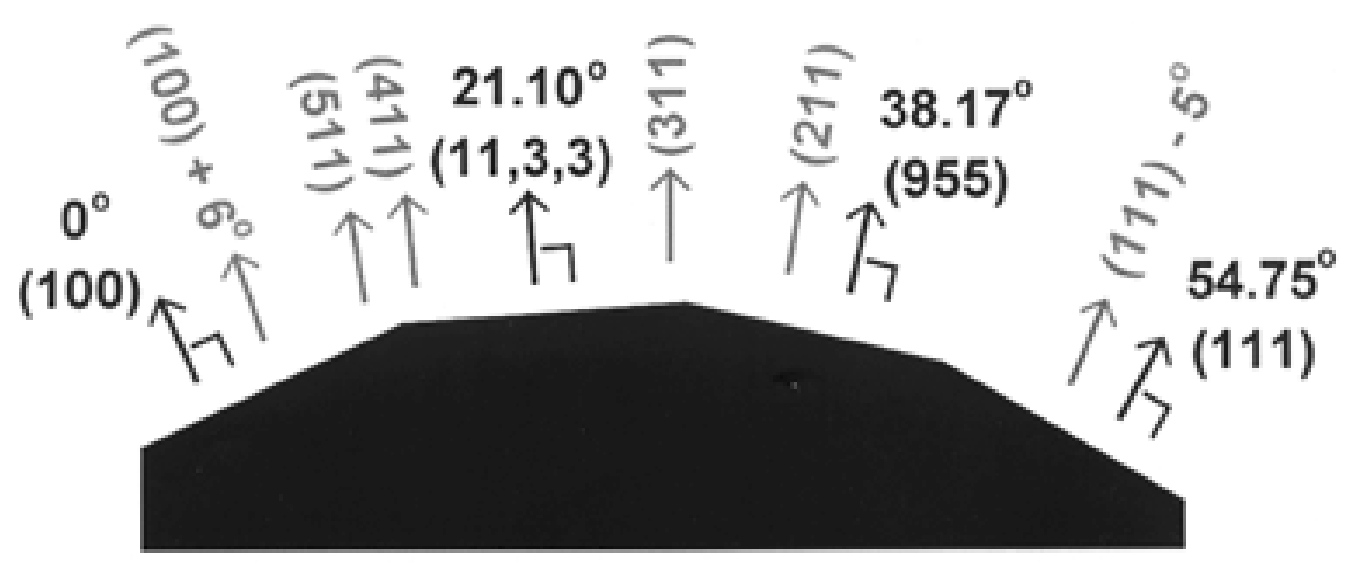

Figure 1: A diagram showing the relative orientations of the various surfaces discussed in this paper.

$\mathrm{As} / \mathrm{Ge}$ refers to an arsenic-exposed Ge surface, whereas $\mathrm{P} / \mathrm{Ge}$ refers to a phosphorous-exposed Ge surface, regardless of the source of arsenic or phosphorous. To specify the exact source of arsenic or phosphorous, a slightly different nomenclature is used. A Ge surface that has been exposed to arsine will be referred to as an $\mathrm{AsH}_{3}: \mathrm{Ge}$ surface. Similarly, a $\mathrm{PH}_{3}$ :Ge surface is a Ge surface that has been exposed to phosphine.

The terms "stable" and "unstable" will have very specific meanings in this paper. A "stable" surface cannot be facetted by $\mathrm{AsH}_{3}$ exposure. In contrast, "unstable" As/Ge surfaces can either facet or remain flat, depending on the exact $\mathrm{AsH}_{3}$ exposure conditions.

\section{Results}

\section{(a) Stable $\mathrm{AsH}_{3}: \mathrm{Ge}(\mathrm{mnn})$ Surfaces} stable.

Under $\mathrm{AsH}_{3}$ etching, $\mathrm{As} / \mathrm{Ge}(100)$, (11,3,3), (955), and (111) surfaces are all

Our results for $\mathrm{As} / \mathrm{Ge}(100)$ and (111) are consistent with earlier studies. The $\mathrm{AsH}_{3}: \mathrm{Ge}(100)$ surface consists of a simple $2 \times 1$ reconstruction in which As dimers terminate the bulk Ge lattice [1,2], as has been observed previously for tertiarybutylarsine-exposed $\mathrm{Ge}$ in an MOCVD environment [3] and for $\mathrm{As}_{2}-$ and $\mathrm{As}_{4}$ exposed Ge in a UHV environment [4-6]. 
As/Ge(111) surfaces formed by As $_{4}$ exposure under UHV consist of a simple $1 \times$ 1 reconstruction in which As atoms terminate the Ge bulk lattice [7-9]. Each As atom is bonded to three Ge atoms, leaving a lone electron pair protruding away from the surface. Although this bonding configuration is very desirable chemically, it places the surface As atoms under tension [10]. It has been shown that this strain produces a network of threeatom-wide trenches [7,8]. The $\mathrm{AsH}_{3}: \mathrm{Ge}(111)$ surfaces we have observed are quite similar and contain all of the same basic features. The only difference is that the trench networks appear to be more hexagonal and more closely spaced for the conditions we have studied.

In contrast to the relatively minor reconstructions and relaxations of the $\mathrm{As} / \mathrm{Ge}(100)$ and (111) surfaces, the $\mathrm{As} / \mathrm{Ge}(11,3,3)$ and (955) surfaces are heavily reconstructed. As seen in Figure 2, the As/Ge(11,3,3) surface consists of parallel ridges spaced $23.6 \AA$ apart, consistent with the observed $1 \times 1$ LEED pattern. This image shows the strong tendency toward $(11,3,3)$. Only $(11,3,3)$ terraces separated by steps are observed.

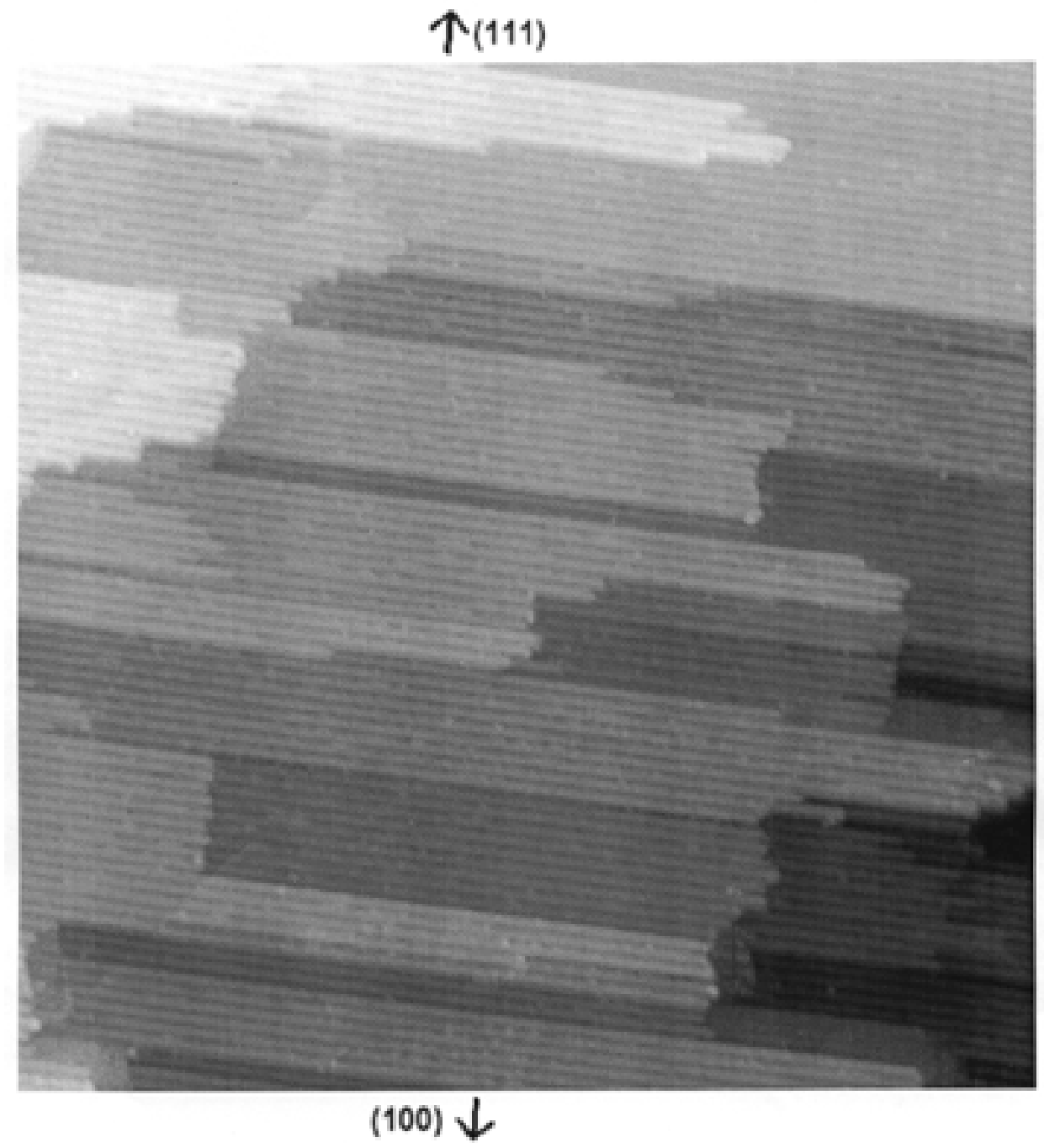

Figure 2: A $2000 \AA \times 2000 \AA$ image of $\mathrm{AsH}_{3}: \mathrm{Ge}(11,3,3)$ annealed under 1.2 torr $\mathrm{AsH}_{3}$ at $560^{\circ} \mathrm{C}$ for 20 minutes, then cooled to room temperature under $\mathrm{AsH}_{3} . \mathrm{V}_{\text {sample }}=-2.0 \mathrm{~V}$ and $\mathrm{I}_{\text {tun }}=0.1 \mathrm{nA}$. 
At slightly higher resolution (Figure 3), several different structural motifs become visible. The principal structures are the regularly spaced parallel ridges. These ridges appear to be very closely related to the double-row steps seen on vicinal As/Ge(100) surfaces [1]. Between each pair of ridges there is a gap. The simplest way to span these gaps appears to be with short sections of (311)-oriented surface. An example is labeled with a "1" in Figure 3. In some locations this gap region has been etched ("2" in Figure 3 ). In other locations a ridge has formed where a gap ought to be ("3" in Figure 3).

Although the atomic structure of these various motifs is unknown, a definite hierarchy exists. The ridges are the most stable structure on the surface. This is evident in Figure 3, where the gaps between ridges are being preferentially etched while the ridges remain intact.

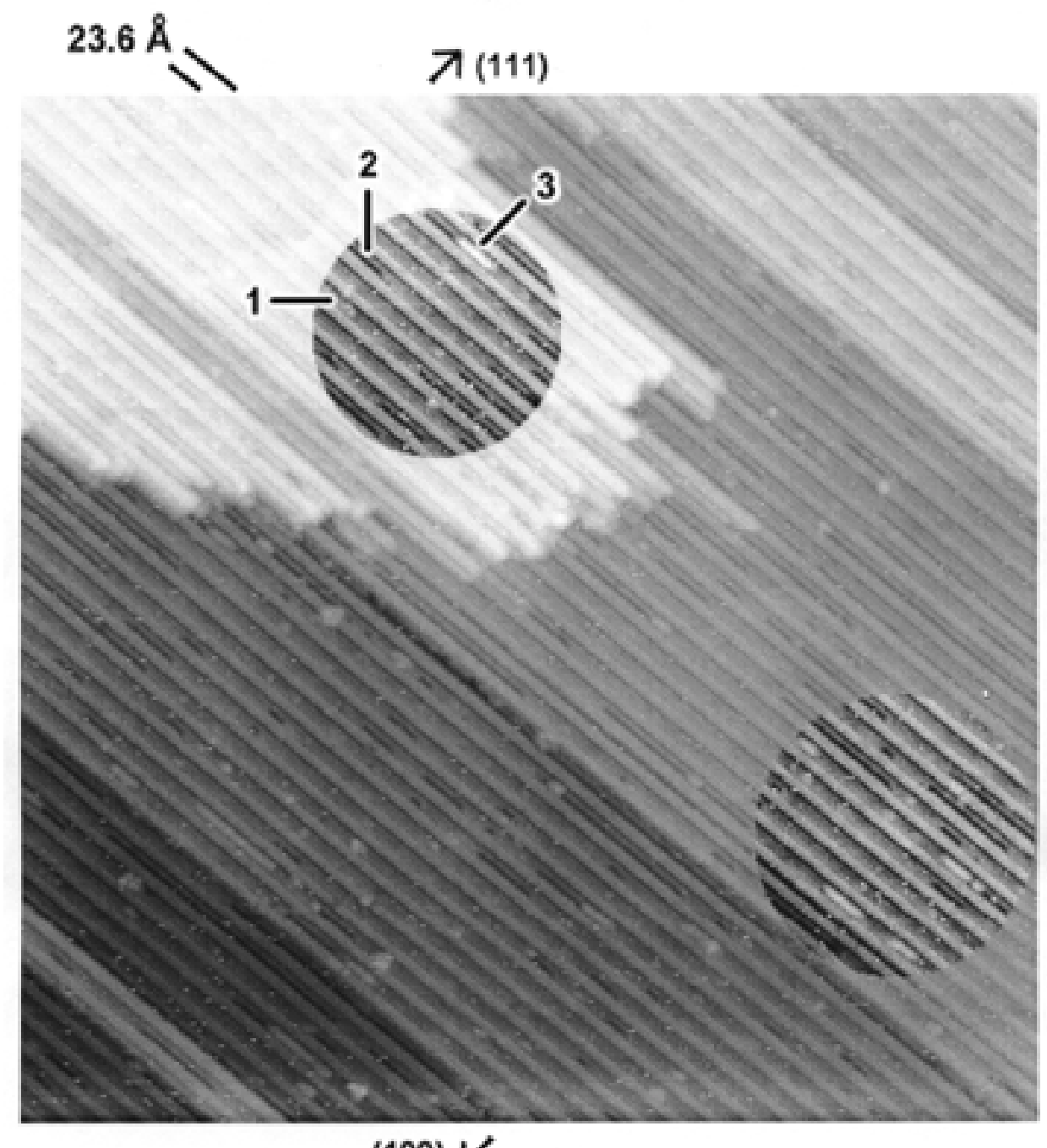

(100)

Figure 3: A higher-resolution $1000 \AA \times 1000 \AA$ image of the $\mathrm{AsH}_{3}: \mathrm{Ge}(11,3,3)$ surface shown in Figure 2. In the two circled regions, the gray scale has been expanded to reveal surface details. An explanation of features "1," "2," and "3" can be found in the text. $\mathrm{V}_{\text {sample }}=-2.0 \mathrm{~V}$ and $\mathrm{I}_{\text {tun }}=$ $0.1 \mathrm{nA}$. 
The final stable surface to be identified in this study is As/Ge(955). Figure 4 shows that the $\mathrm{As} / \mathrm{Ge}(955)$ surface consists of ridges spaced $22.9 \AA$ apart, consistent with the observed $1 \times 1$ LEED pattern. Although it is possible that these (955) ridges are structurally similar to $(11,3,3)$ ridges, their behavior seems quite different.

In particular, it is possible to travel from one (955) terrace to another via a ramp (an example is labeled with an "r" in Figure 4). These ramps are actually "nano-facets" facing toward nearby directions [such as (211) or (533), for example]. These nano-facets are significant. Notice that similar facets do not exist on the $\mathrm{As} / \mathrm{Ge}(11,3,3)$ surfaces shown in Figures 2 and 3. This indicates that $\mathrm{As} / \mathrm{Ge}(11,3,3)$ is much more stable than any nearby facetting direction, whereas $\mathrm{As} / \mathrm{Ge}(955)$ is not.

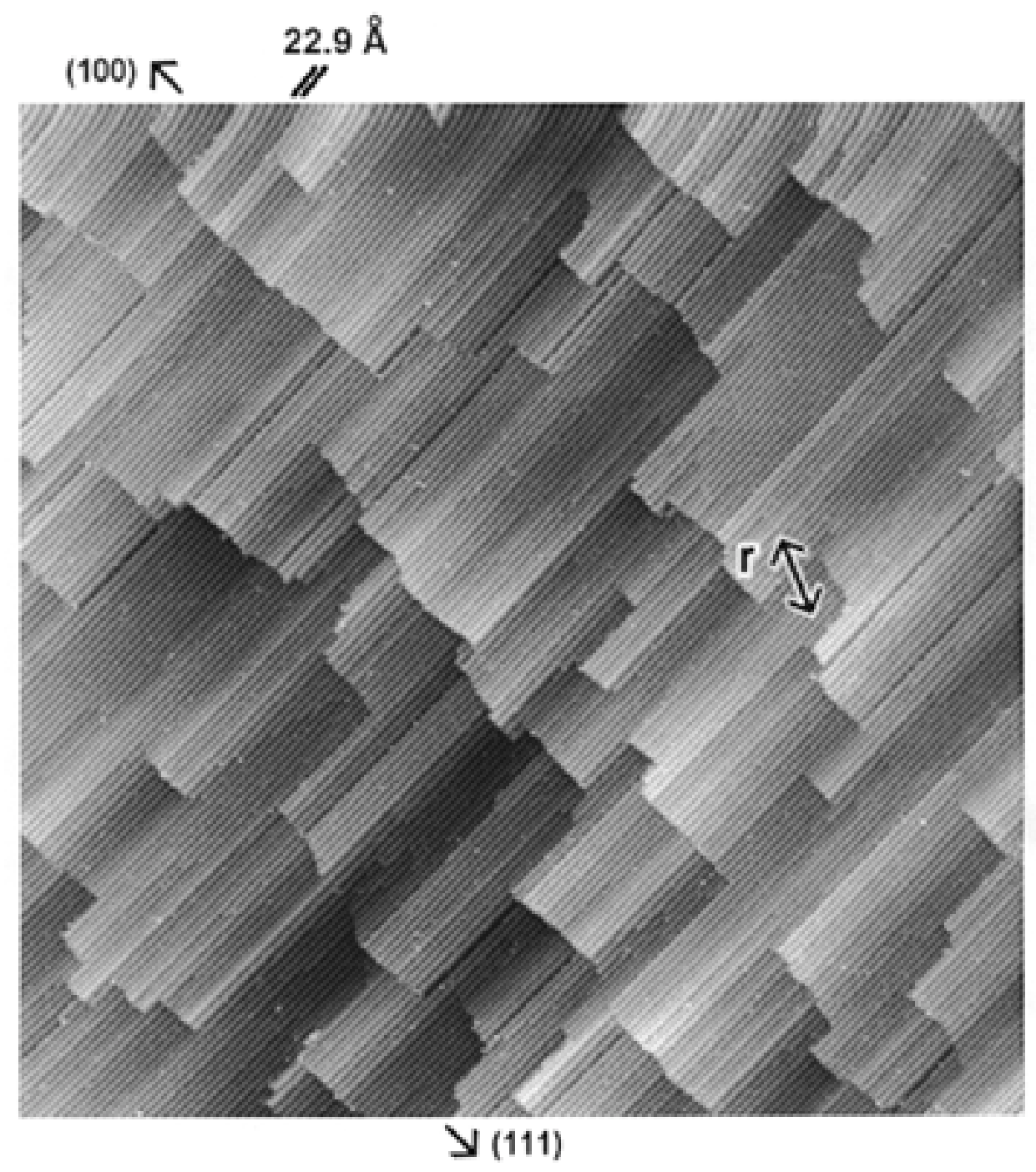

Figure 4: A $3500 \AA \times 3500 \AA$ image of $\mathrm{AsH}_{3}: \mathrm{Ge}(955)$ annealed under 1.2 torr $\mathrm{AsH}_{3}$ at $560^{\circ} \mathrm{C}$ for 20 minutes, then cooled to room temperature under $\mathrm{AsH}_{3}$. A "ramp" between two adjacent (955) terraces has been labeled with an "r" (see text). $\mathrm{V}_{\text {sample }}=-2.0 \mathrm{~V}$ and $\mathrm{I}_{\text {tun }}=0.08 \mathrm{nA}$. 


\section{(b) Unstable $\mathrm{AsH}_{3}: \mathrm{Ge}(\mathrm{mnn})$ Surfaces}

We have studied the effect of $\mathrm{AsH}_{3}$ exposure on many other miscut directions: (511), (411), (311), (211), (100) miscut $2^{\circ}, 6^{\circ}$, and $9^{\circ}$ toward (111), and (111) miscut $5^{\circ}$ toward (100). In each case it is possible to find $\mathrm{AsH}_{3}$ exposure conditions that induce facetting. The degree of facetting seems to depend on many factors, such as miscut angle, annealing time, annealing temperature, $\mathrm{AsH}_{3}$ partial pressure, and background $\mathrm{As}_{4}$ partial pressure. Although the interaction of these factors can become quite complicated, some general trends have emerged.

First of all, when these unstable surfaces facet, they tend to facet toward the stable directions. For example, surfaces miscut within a few degrees of $(11,3,3)$ tend to become vicinal $(11,3,3)$ surfaces, consisting solely of $(11,3,3)$ terraces separated by steps. Similarly, near (100) and (111), there is a tendency toward (100) and (111) facetting, respectively. As noted earlier, the tendency to form (955) facets is not as strong.

Away from these stable directions, the facetting is generally incomplete. As an example, in Figure 5 we show an As/Ge(511) surface that is only partially facetted toward (100) and $(11,3,3)$. In addition to these two stable facetting directions, there are obvious (511) regions and a variety of less obvious intermediate facets.

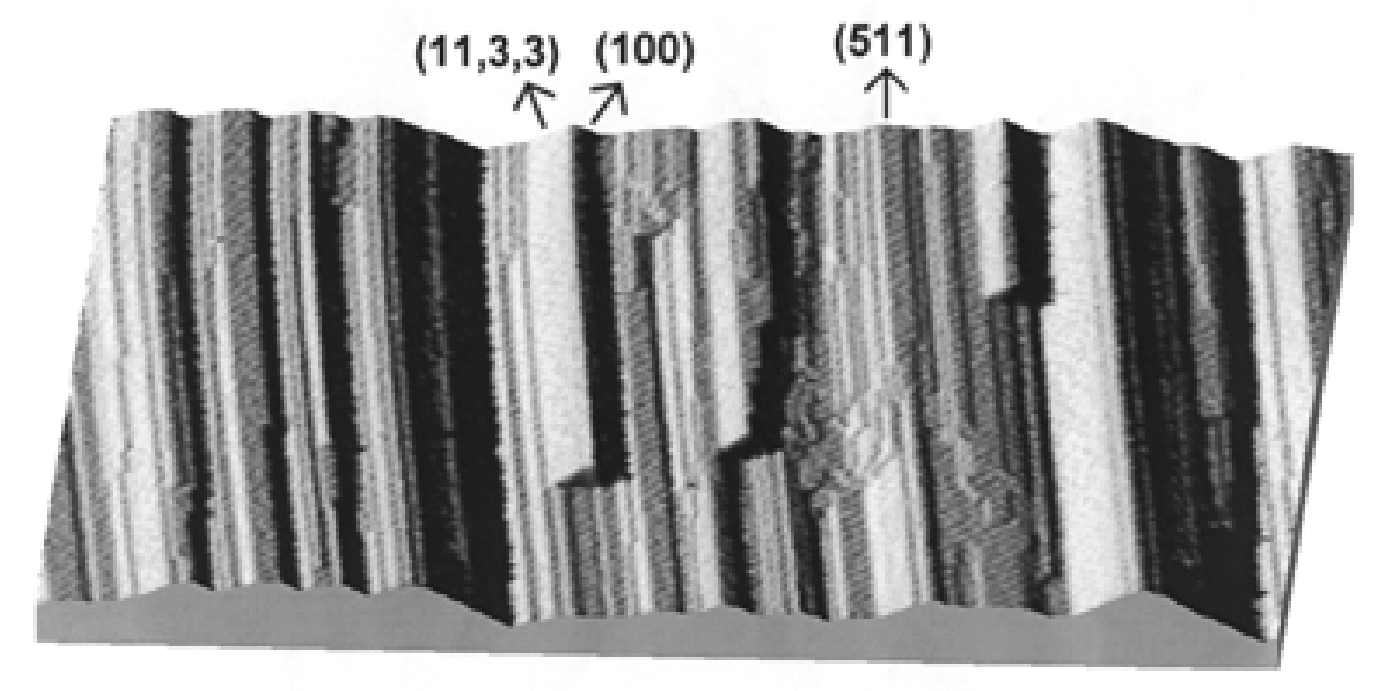

Figure 5: A $1.0 \mu \mathrm{m} \times 1.0 \mu \mathrm{m}$ image of $\mathrm{AsH}_{3}: \mathrm{Ge}(511)$ annealed under 1.2 torr $\mathrm{AsH}_{3}$ at $640^{\circ} \mathrm{C}$ for 30 minutes, then cooled to $300^{\circ} \mathrm{C}$ under $\mathrm{AsH}_{3}$, then cooled to room temperature under $\mathrm{H}_{2}$. This image has been artificially illuminated from the left. The surface has partially facetted toward

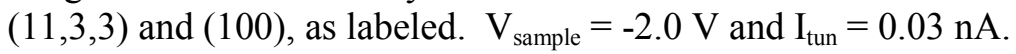

Finally, it is important to note that it is possible to expose an unstable surface to $\mathrm{AsH}_{3}$ without inducing facetting. The most obvious method is to keep the $\mathrm{AsH}_{3}$-etching to a minimum by reducing the temperature, $\mathrm{AsH}_{3}$ partial pressure, and total $\mathrm{AsH}_{3}$ exposure time. Taken to an extreme, background $\mathrm{As}_{4}$ can be used as the sole arsenic source. Under $\mathrm{As}_{4}$ exposure, we observe neither etching nor facetting of the resulting As/Ge surfaces. 
A second, much more effective method is to increase the temperature and reduce the $\mathrm{AsH}_{3}$ partial pressure. This method relies on thermal annealing to flatten the surface. Using this method we have been able to completely flatten even very heavily facetted surfaces.

To give two examples, we have been able to use these methods to obtain very flat vicinal (100) and (111) surfaces. Flat vicinal (100) consists of (100) terraces separated by regularly spaced, four-monolayer $(5.67 \AA$ high) steps. Similarly, flat vicinal (111) consists of (111) terraces separated by regularly spaced steps with a height of $6.53 \AA$ (two bilayers). This is different from facetted vicinal (100) or (111), which consist of large (100) or (111) facets separated by bunched steps and/or other facets.

\section{(c) $\quad \mathrm{PH}_{3}: \mathrm{Ge}(\mathrm{mnn})$ Results}

In contrast to $\mathrm{AsH}_{3}$, etching of Ge by $\mathrm{PH}_{3}$ is negligible. Perhaps for this reason, the morphology of $\mathrm{PH}_{3}: \mathrm{Ge}(\mathrm{mnn})$ surfaces is much simpler. They remain flat under all of the conditions we have studied. So far we have studied $\mathrm{PH}_{3}$ : $\mathrm{Ge}(\mathrm{mnn})$ for (211), (311), (411), (511), and (100) miscut $2^{\circ}, 6^{\circ}$, and $9^{\circ}$ toward (111) under a variety of annealing conditions, and no significant facetting has been observed.

\section{5. $\mathrm{AsH}_{3}: \mathrm{Ge}(\mathrm{mnn})$ Discussion}

Throughout this paper, we have been referring to surfaces as "stable" and "unstable." It is important to note that in this paper, a "stable" surface is not necessarily a low energy surface. Since $\mathrm{AsH}_{3}$ etches Ge, there is a net flow of Ge atoms away from the surface, so the surface is not being held at equilibrium. Therefore, the resulting surface is not necessarily a low energy surface. There could be a kinetic barrier preventing the surface from settling into its lowest energy configuration.

Nonetheless, regardless of the exact reason, it is clear that facetting of the unstable As/Ge surfaces is related to $\mathrm{AsH}_{3}$ exposure and, unavoidably, to the observed etching. It is also known that thermal annealing can completely flatten even the most heavily facetted surfaces. The degree of facetting is therefore the result of a competition between $\mathrm{AsH}_{3}$-induced facetting and flattening of these facets by annealing. Although the $\mathrm{AsH}_{3}$ exposure conditions can be carefully controlled so as to completely flatten or completely facet a surface, most of the surfaces we have observed are in more complicated, partially facetted configurations.

The $\mathrm{PH}_{3}$-exposed surfaces provide a nice counterexample in that no facetting or etching has been observed. Instead, we observe very flat, heavily reconstructed surfaces.

\section{Summary}

In this paper we have studied the effects of $\mathrm{AsH}_{3}$ and $\mathrm{PH}_{3}$ exposure on $\mathrm{Ge}(\mathrm{mnn})$ substrates between (100) and (111). We find that four surface orientations are stable and remain flat under $\mathrm{AsH}_{3}$ exposure: (100), (11,3,3), (955), and (111). We find that $\mathrm{Ge}(\mathrm{mnn})$ surfaces in between these principal directions are unstable under $\mathrm{AsH}_{3}$ exposure. Depending on the exact $\mathrm{AsH}_{3}$ exposure conditions, these unstable surfaces can either facet or remain flat. Under $\mathrm{PH}_{3}$ exposure, no facetting has been observed. For a wide variety of annealing conditions, every miscut direction we have studied has remained flat under $\mathrm{PH}_{3}$ exposure. 


\section{Acknowledgements:}

This work would not have been possible without the help of J. Geisz, A. Kibbler, D. Friedman, S. Kurtz, C. Kramer, M. McCarthy, and K. Jones. In addition, we would like to thank S. B. Zhang for his helpful discussions. This work is supported by the Office of Energy Research, Basic Energy Sciences, U.S. Department of Energy.

\section{References:}

[1] W.E. McMahon and J.M. Olson, Phys. Rev. B60 (1999) 2480.

[2] W.E. McMahon and J.M. Olson, Phys. Rev. B60 (1999) 15999.

[3] S. Gan, L. Li, J. Begarney, D. Law, B.-K. Han, and R. Hicks, J. Appl. Phys. 85 (1999) 2004.

[4] R.D. Bringans, Crit. Rev. Solid State Mater. Sci. 17 (1992) 353.

[5] J.F. Morar, U.O. Karlsson, R.I.G. Uhrberg, J. Kanski, P.O. Nilsson and H. Qu, Appl. Surf. Sci. 41/42 (1989) 312.

[6] P.R. Pukite and P.I. Cohen, J. Crystal Growth 81 (1987) 214.

[7] R. Becker and J. Vickers, J. Vac. Sci. Tech. A8 (1990) 226.

[8] R.S. Becker, T. Klitsner, and J.S. Vickers, J. Microscopy 152 (1988) 157.

[9] R.D. Bringans, R.I.G. Uhrberg, R.Z. Bachrach and J.E. Northrup, Phys. Rev. Lett. 55 (1985) 533.

[10] R.D. Meade and D. Vanderbilt, Phys. Rev. Lett. 63 (1989) 1404. 